\title{
Sombras y luces de la melancolía
}

Contemporánea de la de Freud, la obra psicopatológica de Jules Séglas (1856-1939) sigue conservando la frescura y la perspicacia de los mejores análisis semiológicos y las más penetrantes descripciones clínicas surgidas a lo largo del siglo XIX, «el siglo de la clínica» según la expresión con que Rafael Huertas titula su última monografía ${ }^{1}$. Fue Séglas un alienista poco dado a las grandes síntesis teóricas, modesto en pretensiones de establecer una doctrina de la patología mental y, por naturaleza, escasamente inclinado a alistarse en cualquiera de las corrientes de pensamiento imperantes en su tiempo, provinieran éstas de uno u otro lado del Rin. Por contra, sea cual sea el ámbito tratado, su obra es el testimonio directo de su gusto por una forma sutil de observación, indagación y análisis de las manifestaciones clínicas, un quehacer principalmente descriptivo y semiológico llevado a cabo con enorme sencillez y buenas dosis de originalidad. Las características que acaban de apuntarse hicieron de Séglas un referente insustituible entre sus colegas y muchos alumnos, una autoridad para las siguientes generaciones de psiquiatras que, como Clérambault, Ey o Lacan, siguieron viendo en sus descripciones la clínica de la observación en su estado más puro.

$\mathrm{Su}$ carrera profesional se desarrolló en los manicomios de Bicêtre y la Salpêtrière, donde se jubiló en 1921. Como hicieran algunos otros grandes alienistas que le precedieron, también Jules Séglas impartió una enseñanza clínica en su Servicio de la Salpêtrière. Debido al interés suscitado y a la insistencia manifestada por los alumnos y asistentes, publicó en 1895 sus Leçons cliniques sur les maladies mentales et nerveuses. El volumen, de 835 páginas, recoge las veintiocho lecciones dictadas por Séglas entre 1887 y 1894, editando las anotaciones tomadas por algunos de los asistentes, en especial por Henry Meigne, el principal impulsor de la publicación ${ }^{2}$. Es de destacar, como el propio Séglas advierte en el prefacio, que estas lecciones clínicas no pretenden una revisión crítica del problema tratado bajo la forma de un breve ensayo; son, por el contrario, una «demostración» que procura mantenerse en el estricto marco derivado del «punto de vista de la observación clínica».

\footnotetext{
HuERTAs, R., El siglo de la clínica, Madrid, Frenia, 2004.

SÉGLAS, J., Leçons cliniques sur les maladies mentales et nerveuses (Salpêtrière 1887-1894). Recueilles et publiées par le Dr. Henry Meigne, París, Asselin y Houzeau, 1895.
} 
Los temas explorados abarcan muy distintos ámbitos psicopatológicos, siendo especialmente meritorias las lecciones dedicadas a las alucinaciones, la obsesión, la melancolía, la paranoia y los delirios de negaciones. Son también éstas las cuestiones a las que consagró sus publicaciones más importantes. Tomando como referencia los modelos surgidos a partir de los estudios sobre las afasias, investigó inicialmente el fenómeno alucinatorio en Des troubles du langage chez les aliénés (1892), monografía coronada por las descripciones de las alucinaciones psicomotrices verbales, una variante muy sutil de las alucinaciones psíquicas de Baillarger ${ }^{3}$; con el paso de los años, sin embargo, Séglas abandonaría ese tipo de explicaciones neurológicas hasta perfilar los rudimentos de una concepción psicológica de la alucinación, ahora considerada como «patología del lenguaje interior» ${ }^{4}$. Por su parte, las obsesiones y el conjunto de los signos de la patología mental fueron minuciosa y sistemáticamente explorados en la amplia contribución «Sémiologie des affections mentales», incluida en el Traité de G. Ballet ${ }^{5}$. La paranoia o folie systématisée primitive, pese a las enormes complicaciones que siempre ocasionó al discurso médico de las enfermedades mentales -Séglas decía de ella que era la noción peor definida en psiquiatría ${ }^{6}$-, permaneció siempre en su punto de mira, manteniendo sobre el particular una posición nosográfica contraria a la paulatina reducción impuesta por Kraepelin ${ }^{7}$. La melancolía y los delirios de negaciones $^{8}$, por último, alcanzaron con los trabajos de Séglas y Cotard las descripciones fenomenológicas más detalladas y precisas, avistando de lejos, especialmente a través de las ideas delirantes de condena e inmortalidad, de incapacidad y autoacusación, la metapsicología que Freud comenzaba a elaborar en esos mismos años sobre el drama melancólico.

En lo que atañe al extenso ámbito que la tradición venía nombrando con el término 'melancolía', una profunda transformación sobrevino a medida que se desarrolló el discurso psiquiátrico de las enfermedades mentales. Aquella «fascinante constelación de antiguos problemas y angustias que a lo largo de siglos la historia de Occidente ha guardado en su memoria», según palabras de R. Bartra9, terminaría por reducirse a una mera enfermedad, de la cual, con el paso de las

SÉGlas, J., Des troubles du langage chez les aliénés, París, Rueff, 1892.

SÉGlas, J., «Préface», en H. Ey, Hallucinations et délires, París, Alcan, 1934.

5 SÉGlas, J., «Sémiologie des affections mentales», en G. BALlet, Traité de Pathologie mental, París, Dion, 1903, pp. 74-270.

6 SÉGLAS, J., «La paranoïa: historique et critique», Archives internationales de Neurologie, 1887, t. XIII, pp. 62-76; 221-232; 393-406.

7 Séglas, J., «La démence paranoïde», Annales Médico-psychologiques, 1900, t. II, pp. 232-246.

8 SÉGlas, J., Le délire des négations, París, Masson, 1897.

9 BARTRA, R., Cultura y melancolía. Las enfermedades del alma en la España del Siglo de Oro, Barcelona, Anagrama, 2001, p, 9. 
décadas, se extraerían las mimbres que habrían de dar forma al concepto actual de «depresión», tan omnipresente como inespecífico. Esta transmutación de la melancolía antigua en la depresión contemporánea tuvo en Esquirol al primer partidario decidido cuando propuso sustituir dicho término por el de lypémanie: «La palabra melancolía -escribió en 1819- empleada en el lenguaje vulgar para expresar el estado habitual de tristeza de algunos individuos, debe dejarse a los moralistas y a los poetas, quienes, en sus expresiones, no están obligados a tanto rigor como los médicos» ${ }^{10}$.

En adelante, a través de Baillarger, J.-P. Falret, Griesinger y Kraepelin, la reunión de la manía y la melancolía afianzaría esa estrecha perspectiva según la cual la melancolía, fuera o no delirante, constituía una enfermedad que cumplía todos los requisitos exigidos por la medicina positivista. Desde otro punto de vista, aunque apuntando en la misma dirección, la obra de Adolf Meyer contribuyó decisivamente a la transformación de la melancolía -término que encontraba «presuntuoso»- en depresión. Siguiendo estas indicaciones, Wendell Muncie, uno de sus seguidores, se encargaría de generalizar esta noción al considerar que la tristeza era lo verdaderamente predominante en las reacciones depresivas. Fue así como Muncie concluyó que existían dos tipos de depresiones, una "patológica» y otra «normal», razón por la cual la consideró «una experiencia universal» ${ }^{11}$. De la mano de esta medicalización de la tristeza se ha venido produciendo una devaluación de la responsabilidad subjetiva, de las obligaciones para con el trabajo y la familia, cosa de la que somos testigos a diario en nuestro trabajo institucional cuando alguien nos plantea de entrada su condición de enfermo depresivo y reclama los beneficios que dicha condición le confiere.

También es en esta corriente de medicalización de la melancolía donde deben inscribirse las contribuciones de Séglas y el grupo de la Salpêtrière. A decir de Séglas, la enfermedad melancólica consiste en una alteración de la personalidad ocasionada por ciertas modificaciones de base orgánica. Dichas modificaciones se manifiestan en experiencias de «dolor moral», las cuales, en ocasiones, pueden llegar a inducir ideas delirantes características. De acuerdo con esta concepción nosológica, el autor describe las dos grandes formas nosográficas en las que podemos reconocer a la «psiconeurosis» melancólica: la melancolía simple y la melancolía delirante. Una y otra forma comparten un sustrato o fondo común, aunque su gravedad, sus manifestaciones clínicas y la modalidad particular de la experiencia subjetiva las diferencian abiertamente.

10 Esquirol, J.-E.-D., Dictionnaire des sciencies médicales, par une Société de Médecins et de Chirurgiens, T. XXXII, Méd-Més, París, Panckoucke, 1819, p. 148.

11 Muncie, W., Psychobiology and Psychiatry. A Text-book of Normal and Abnormal Beahavior, St. Louis, C. V. Mosby, 1939. 
Observada sobre todo entre los pacientes de consulta privada y raramente entre los ingresados en manicomios, la melancolía sin delirio (melancolía simple) se caracteriza por la presencia exclusiva de «fenómenos elementales, fundamentales», esto es, por un estado de pereza, de abulia intelectual y de colapso psíquico. Además de este conjunto de manifestaciones básicas, resulta característico que todas ellas son vividas por el enfermo de forma consciente y dolorosa («dolor moral»). Por contra, el cuadro clínico de la melancolía delirante, observado principalmente en los asilos, se define por sumarse a las alteraciones fundamentales el «trastorno del contenido de las ideas»: «ideas de ruina, de humildad, de incapacidad, de autoacusación, de culpabilidad para con la sociedad, para con Dios; ideas de condenación eterna, de persecución, temor de castigos, de suplicios, del infierno, y en ocasiones ideas más especiales de negación y de inmortalidad $[\ldots]{ }^{12}$.

Tal es, de manera muy simplificada, la concepción séglasiana de la melancolía. Conforme a esta visión nosológica, las ideas delirantes melancólicas surgen siempre de forma secundaria a los síntomas fundamentales que definen la melancolía simple. Se concluye así, «desde una perspectiva psicológica», que los trastornos cenestésicos, los emocionales (dolor moral) y los que afectan al cabal desempeño de las operaciones intelectuales (trastornos de la formación de ideas, colapso psíquico y abulia) componen el subsuelo en el que germinarán las ideas delirantes, las cuales toman su contenido de esos trastornos fundamentales.

Sólo unos meses separan estas conferencias de Séglas del «Manuscrito G» de Freud, también dedicado a la melancolía, aunque sus enfoques distan notablemente. La perspectiva de Freud se centra en las relaciones que el sujeto melancólico mantiene con los otros. Esas relaciones de objeto muestran una amplia gama afectiva, la que va del odio al amor pasando por la ambivalencia; se añade a los anteriores tipos de relación una de particular interés en el caso de la melancolía: la identificación al objeto. Se trata, por tanto, de una modalidad de análisis que trata de explicar la afección melancólica investigando las heridas consustanciales a la condición humana, poniendo de manifiesto las dificultades con el deseo e incidiendo sobre las relaciones entre el ser y la falta.

Partiendo de este enfoque, Freud advierte en 1895: «el afecto correspondiente a la melancolía es el del duelo, o sea, la añoranza de algo perdido. Por tanto, acaso se trate en la melancolía de una pérdida, producida dentro de la vida pulsional»13. Dos décadas después, en su artículo memorable «Duelo y melancolía», esta hipótesis original será desarrollada, tratando con ella de esclarecer la quinta-

2 SÉGLAS, J., Leçons cliniques, p. 297 (Lección XI: «Le délire dans la mélancolie»).

13 Freud, S., «Manuscrito G. Melancolía», Sigmund Freud. Obras Completas, T. I, Buenos Aires, Amorrortu, 1976, p. 240. 
esencia de la afección melancólica al compararla con el duelo normal producido por la pérdida consciente de un objeto amado. Aunque el duelo y la melancolía comparten la misma vocación afectiva, el mismo tipo de dolor emocional y aflicción somática, ambas mostrarán a la postre su radical oposición. Al desarrollar su análisis comparativo, Freud irá paulatinamente afianzando los conceptos fundamentales que caracterizan su concepción: pérdida, objeto, yo, narcisismo y autorreproche.

Diferenciándola del duelo, Freud considera que la melancolía se origina a consecuencia de una pérdida de objeto «sustraída a la conciencia», pérdida que resulta un tanto misteriosa por cuanto el sujeto sabe «a quién perdió, pero no lo que perdió en él». Tan singular forma de pérdida modula el conjunto de la experiencia de la melancolía, cuyas características clínicas se especifican «en lo anímico por una desazón profundamente dolida, una cancelación del interés por el mundo exterior, la pérdida de la capacidad de amar, la inhibición de toda productividad y una rebaja en el sentimiento de sí que se exterioriza en autorreproches y autodenigraciones y se extrema hasta una delirante expectativa de castigo» ${ }^{14}$. A diferencia del duelo, con el que comparte el resto de las manifestaciones clínicas, la melancolía se caracteriza por el enigma relativo al objeto perdido y por el despiadado autorreproche dirigido hacia el yo. Siguiendo las pesquisas a las que conducen estos dos caracteres diferenciales, dará Freud con lo más particular que aflige al melancólico.

Mientras en el duelo el mundo exterior aparece «desierto y empobrecido ante los ojos del sujeto», la pasión del melancólico se asienta en el autorreproche dirigido hacia su propio yo, al que trata de «indigno de toda estimación [...] moralmente condenable». Siguiendo la argumentación freudiana, el afecto melancólico es el resultado de una pérdida de objeto y esas autoacusaciones con que el sujeto se martiriza son en realidad «quejas» que él dirige a otra persona. Esta interpretación del autorreproche como heterorreproche encubierto -del cual, por lo demás, se obtiene cierta satisfacción-se basa en la consideración de que esa pérdida enigmática ha ocasionado un terrible marasmo en el yo. De resultas de esta afectación, el yo es tomado como un objeto, como el objeto perdido, razón por la cual el sujeto alardea sin el menor pudor de sus miserias más despreciables.

Aunque de manera muy sucinta se han expuesto los puntos de vista de Séglas y de Freud respecto a la melancolía, es posible apreciar entre ellos diferencias significativas. Los del alienista de la Salpêtrière se enmarcan en el discurso médico de las enfermedades mentales y promueven un análisis diacrónico de los síntomas,

14 Freud, S., «Duelo y melancolía», Sigmund Freud. Obras Completas, T. XIV, Buenos Aires, Amorrortu, 1976, p. 242. 
es decir, una explicación de las manifestaciones de la enfermedad de acuerdo con el orden cronológico de su aparición. El análisis de Freud, por el contrario, investiga la melancolía desde una perspectiva tradicional, esa que la liga con un tipo de pérdida que, al no poder ser elaborada mediante el duelo, aboca al sujeto al suplicio del autodesprecio y al sentimiento de indignidad.

José María Álvarez y Juan J. de la Peña Esbrí 